\title{
ANIMA, SPIRITUS, MENS Y ANIMUS EN LA SUMA CONTRA LOS GENTILES DE TOMÁS DE AQUINO
}

\author{
Gabriel Martí Andrés \\ Universidad de Málaga
}

\begin{abstract}
RESUMEN
La diversificación moderna de los saberes sobre el ser humano ha llevado a una visión diversificada de la antropología tomista. Se impone una vuelta revitalizadora a esta antropología que muestre la unidad estructural que para Santo Tomás tienen el alma y el hombre. El trabajo se centrará en las tres tesis que articulan la teoría tomista del espíritu y, en concreto, la exposición que nuestro autor hace en la Summa contra gentiles, obra capital en la producción del Angélico que, sin embargo, ha sido bastante marginada.
\end{abstract}

Palabras clave: Santo Tomás de Aquino, spiritus, anima, mens, animus.

\begin{abstract}
The modern diversification of the knowledges about the human beings has become to a diversificated vision of the anthropology of Saint Tomas. It is imposed a revived return to this anthropology that shows the structural unity that soul and man have for the author. The work will be centred in the three thesis that articulate the teory of Saint Tomas about the spirit and, concretely, the exposition our author makes in Summa contra gentiles, main work in his production which, nevertheless, has been so rejected.
\end{abstract}

Key words: Saint Tomas, spiritus, anima, mens, animus.

\section{INTRODUCCIÓN}

El hombre siempre ha ocupado un lugar central en la especulación filosófica. Sin embargo, en la modernidad se adquiere conciencia de la posibilidad de una Antropología como saber independiente de disciplinas tales como la Estética o la Ética por un lado y la Metafísica por otro, produciéndose un cambio profundo de perspectiva en esta dirección. Pues bien, con una Antropología tal se gana en sistematicidad, pero se pierde en contenido, la irreductibilidad del ser humano aparece con mayor nitidez, pero su base metafísica (constitución y ubicación) y su unidad desaparecen tras la diversificación de saberes. Esta diversificación moderna de saberes da lugar a una visión también diversificada de la antropología antigua y medieval.

La filosofía griega se desvivió por elucidar la pluridimensionalidad del hombre en el marco de la unidad de su ser y en el de la totalidad de lo real; la filosofía medieval pretomista tuvo discrepancias y afinidades con respecto a los antiguos, pero siguió en la misma línea de respeto al ser-uno 
del hombre y de atención a su estructuración metafísica. Tomás de Aquino recogió y elevó hasta cotas altísimas este espíritu, conjugándose a la perfección en su presentación de la realidad del homo su unidad y su complejidad, su singularidad y su pluralidad de referencias; en el Doctor Angélico las doctrinas integradoras y las visiones de conjunto confluyen y son armonizadas con la propia conceptualización de la entidad personal en una síntesis superior. Hay que volver a esta antropología para recuperar la orientación y dar plenitud de sentido a los valiosos descubrimientos de la filosofía moderna y contemporánea.

Ahora bien, la visión tomista del hombre está articulada alrededor del concepto de espíritu; la dimensión espiritual es en el pensamiento del Aquinate la piedra angular de toda la estructura unitaria que es el ser humano. El alma intelectual es concebida por el Santo como el asiento del intelecto, de la voluntad, de la libertad, y lo que da movimiento, vida y sentido al todo. Para él, «como forma sustancial del hombre y acto primero de la materia, es el principio radical y la razón suficiente de todas las manifestaciones de la vida del hombre. Más todavía: el alma humana produce todas las modificaciones, accidentes, formas, determinaciones que hay en el hombre, sin excluir la actualidad y determinación del cuerpo». ${ }^{1}$ Así, el alma intelectual, sus potencias, los actos intelectuales y su relación con los «deseos del corazón», los hábitos... son asuntos constantes en la obra del Doctor Angélico que encuentran cumplida realización en los conceptos aristotélicos, adoptados por Santo Tomás, de anima y substantia intellectualis y en las elaboraciones tomistas alrededor de las nociones de mens, animus y spiritus entre otras. Por ello, el regreso a la antropología tomista habrá de tomar al alma como punto de referencia. En tanto que principio de vida y de movimiento en el hombre, el alma espiritual también goza de unidad estructural para nuestro autor como veremos.

La teoría del alma ha tenido una evolución lineal. A Aristóteles debemos el haber dado los primeros pasos en firme. Pero sólo los primeros. Santo Tomás es uno de los más inquietos seguidores del Estagirita. Este talante llevó al Santo a percatarse de las deficiencias y limitaciones de los planteamientos aristotélicos, superándolos y ofreciéndonos como resultado una obra en la que los valiosos descubrimientos del maestro dejan gran espacio a las nuevas aportaciones del discípulo. Pero esto no es todo. La psicología aristotélica y su desarrollo posterior en Tomás de Aquino están muy presentes en la modernidad. Las modernas nociones de espíritu y alma, desarrolladas especiaimente por el Idealismo alemán gracias a la vía abierta por el Meister Eckhart, discípulo aventajado del Aquinate, deben mucho a las concepciones antigua y medieval. Por lo demás, el pensamiento en general y la antropología en particular del Doctor Angélico gozan en la actualidad de gran vigencia. Prueba de ello es el incremento de escritos en los últimos años sobre el particular, especialmente en EE.UU.

Pero, ¿por qué la Suma contra los gentiles? La Summa contra gentiles ${ }^{2}$ es un texto fundamental en la obra del Angélico al que, sin embargo, se le ha prestado una escasa atención. En él se van

1 Mosaico cultural, Sistemas filosóficos, Madrid, Delblán, 1969, C. 12, pag. 5.

2 La edición con la que vamos a trabajar es:

Tomás de Aquino, Stma contra los gentiles (ed. bilingüe), Madrid, BAC, 1967.

En esta edición se reproduce el texto íntegro de la Suma, a excepción de las jaculatorias que aparecen diseminadas por los márgenes del manuscrito y que, como dice S. Ramírez, constituyen expresiones directas del corazón (cfr. Ramírez, S., Introducción a la Suma teológica (ed. bilingüe), Madrid, BAC, 1947, I, pag. 62). El original de la obra se encuentra en la Biblioteca Vaticana. Las referencias irán acompañadas del número de página y del volumen en este orden. 
cuajando las tesis básicas que más adelante, sobre todo en la Suma teológica, se van a desarrollar extensamente. Por lo demás, la Contra gentiles es una obra vinculada en sus orígenes a nuestro país. Dice M.-D. Chenu:

Une longue tradition veut que saint Thomas ait composé son ouvrage à la requête de Raymond de Penafort, ce dominicain catalan, ancien maître général des Prêcheurs, qui, hanté par la présence des Maures en terre d'Espagne et par l'espérance nouvelle de convertir l'Islam, aurait demandé à son jeune confrère d'equiper les missionnaires des armes intellectuelles nécessaires. ${ }^{3}$

Como afirma J.M. de Garganta, la autoridad y rigor histórico de Pedro Marsili, iniciador de esta «larga tradición», junto con la constatación del hecho de la participación de Tomás de Aquino en el capítulo general de Valenciennes de 1259 y la datación generalizada y acreditada de la redacción de la Summa (1259-1264), no dejan lugar a la duda: la Suma contra los gentiles constituye la aportación de Santo Tomás al proceso de cristianización emprendido por Raimundo de Peñafort en las tierras recién conquistadas de Cataluña y Valencia por el rey Jaime. ${ }^{4}$

Seguiremos en nuestro trabajo un orden descendente, es decir, del todo a las partes. Y es que a la hora de abordar la investigación de una realidad concreta, lo primero es una consideración global dirigida à la índole de su naturaleza. Una vez hecho esto, hay que penetrar en su esencia y poner al descubierto su estructuración interna. Así, comenzaremos por observar la condición del alma humana para, posteriormente, exponer su organización interior; esto siempre, claro está, en Tomás de Aquino. Ahora bien, Sto. Tomás entiende la constitución interna del alma en términos hilemórficos: el espíritu cuenta con una materia y con una forma. En nuestra investigación abordaremos primero el aspecto material y luego el formal. Pero, ¿qué sentido tiene hablar de la materia de lo inmaterial? Y es que la composición materia-forma se puede entender de dos modos: en sentido estricto y en sentido lato. En sentido estricto, apunta exclusivamente a la estructura del ente corpóreo; en sentido lato, puede hacer referencia a cualquier realidad. En efecto, se puede hablar de la materia y la forma de un discurso, de los objetos formal y material de una ciencia y también de la materialidad y formalidad de una sustancia inmaterial en sentido estricto. La materia del alma en este sentido sería aquello que la conforma, y la forma, su configuración externa. El sentido amplio queda muy bien reflejado en las primeras definiciones que de estos términos nos da la Real Academia de la Lengua Española en su Diccionario: materia es la «realidad primaria de la que están hechas las cosas» ${ }^{5}$ y forma es la «figura o determinación exterior de la materia», la «disposición o expresión de una potencialidad o facultad de las cosas». ${ }^{6}$ Este es el sentido en el que se puede hablar de materia y forma en el espíritu tal y como lo entiende el Doctor Angélico. Esta dualidad de sentidos queda perfectamente contemplada por Sto. Tomás en el siguiente texto:

3 Chenu, M.-D., Introduction a l'étude de saint Thomas d'Aquin, Montreal, Institut médiéval de Montréal, 1974, pags. 247-248. $15 / 17$.

4 Cfr. Garganta, J.M. de, Introducción a Ia Suma contra los gentiles (ed. bilingüe), Madrid, BAC, 1967, pags. 14-

5 Real Academia de la lengua española, Diccionario de la Lengua Española, Madrid, Espasa-Calpe, 1992, II, pag. 1336.

6 Ibidem, pag. 984, La cursiva es mía. 
Diversarum rerum diversae sunt materiae: non enim est eadem materia spiritualium et corporalium $(421, \mathrm{I})$.

En esta línea se inscribe una tesis que Tomás de Aquino atribuye a Aristóteles:

Dicit enim, primo, quod, sicut in omni natura est aliquid quasi materia in unoquoque genere (...): necesse est et in anima esse has differentias. Et huiusmodi quidem, scilicet quod in anima est sicut materia, est intellectus (possibilis) in quo fiunt omnia intelligibilia (645, I).

Algunos predecesores y contemporáneos de nuestro autor, recuerda Kenny, como Ibn Gabirol y San Buenaventura también atribuyen al alma intelectual la composición de materia y forma. ${ }^{7}$ Lo hacen de modo explícito y su postulado resulta bastante ilustrativo. Sin embargo, entre la tesis de estos autores y la del Santo de Aquino existe una diferencia importante: la materia que aquéllos adscriben al alma es un cuerpo, espiritual ciertamente, pero un cuerpo al fin y al cabo. ${ }^{8}$ Ahora bien, en tanto que nuestro autor utiliza los términos en cuestión para referirse a la estructura del alma con la intención directa de exponer la doctrina propia sólo una vez y de un modo marginal, es preferible hablar de compósición sustantiva y configuración.

Siempre ateniéndonos al pensamiento de Tomás de Aquino, podemos establecer la siguiente clasificación. Existen una configuración específica y una configuración individual; la individual puede tener aspectos naturales y aspectos adquiridos; por último, dentro de este último grupo se encuentran los caracteres actuales y los habituales. Tanto la configuración específica como la individual natural y la individual adquirida actual consisten en disposiciones fundamentalmente de (ontológicas, aunque también operativas) asociadas a la dotación facultativa. En cambio, la configuración individual adquirida habitual se trata de disposiciones fundamentalmente para vinculadas a la operatividad del anima (es una dispossitio ad (a, para, hacia), ordenada a la acción). ${ }^{9}$ Pues bien, la configuración dispositiva ontológica, en tanto que derivada inmediatamente de la composición sustantiva, corresponde a la mens y la configuración dispositiva operativa al animus.

\section{ANIMA Y SPIRITUS: LA ESPIRITUALIDAD}

En el lenguaje cotidiano ambos términos, 'alma' y 'espíritu', suelen hacerse equivaler en torno a un referente común, a saber, la dimensión incorpórea del ser humano. Sin embargo, en Santo Tomás hay matices que, si bien no hacen posible una diferenciación sustancial, harían injusta la igualación.

7 Cfr. Kenny, A., Aquinas on mind, Londres, Routledge, 1993, pag. 139.

8 Cornelio Fabro, basándose en unos textos de Quodlibeta $I I I$, recoge un segundo sentido de la expresión 'materia de lo inmaterial' en la obra del Doctor Angélico: «San Tommaso (...) si mostra disposto ad ammettere anche nell' angelo e nell'anima umana una composizione di materia e forma, qualora (...) ogni potenza debba esser detta materia, de ogni atto, forma» (Fabro, C., Esegesi tomistica, Roma, Libreria Editrice della Pontificia Università Lateranense, 1969, pag. 134).

9 Está claro que la referencia a una cuádruple configuración en el espíritu es sólo un recurso analítico; el alma goza para Tomás de Aquino de una configuración determinada por aspectos específicos, individuales naturales, individuales adquiridos actuales e individuales adquiridos habituales. 
Dos frases textuales de la Summa nos van a servir para fundamentar nuestra primera tesis: «...humana natura ex anima ex corpore constituatur...» $(798$, II $)$ y «homo autem ex spirituali et corporali natura conditus est» $(513, \mathrm{II})$. En estos textos el autor establece una correspondencia cuerpocuerpo/alma-espíritu y se refiere a anima y corpus como las partes integrantes de la naturaleza humana y a spiritualis y corporalis como las condiciones de dicha naturaleza. En este sentido, los conceptos de anima y spiritus, sin referirse a sustancias diversas en el hombre, se resisten a la identificación. Estableciendo un fácil paralelismo, podemos decir que el cuerpo del hombre es de naturaleza corporal y su alma, de naturaleza espiritual, lo cual es como decir que el alma humana es un anima spiritualis. ${ }^{10}$

Con esto, el alma humana tiene una cualidad que la hace superior a las propias de los vivientes no inteligentes, a saber, la espiritualidad; el alma humana es la única que es, además, espíritu. Ahora bien, el alma no es el único ente de condición espiritual, pues Dios (Tomás de Aquino habla de «Spiritus Dei» $(720$, II)) y el ángel (al que nuestro autor considera «res spiritualis» $(539$, II)) también gozan de espiritualidad. ${ }^{11}$ Así, espiritual es la índole del alma humana, de la sustancia separada y de Dios; o lo que es lo mismo, el alma del hombre, el ángel y Dios son sustancias espirituales o espíritus (esto no es exacto con respecto a Dios, como ahora veremos, pero nos vale dicho a título aproximativo). Si bien el alma nos pone en relación con los animales y las plantas, su espiritualidad nos conecta con los ángeles y con Dios.

Pero, ¿en qué consiste esta espiritualidad? La espiritualidad ha de ser algo común a las sustancias inteligentes y algo exclusivo de ellas. Además, ha de ser un carácter, pues ya hemos dicho que se trata de una condición del alma humana. ${ }^{12}$ Por tanto, no puede consistir en ningún componente sustantivo (potencias) de lo inmaterial. Tampoco puede referirse a la disposición habitual del alma. Pues bien, además de esto, en lo único en lo que coinciden privativamente las sustancias intelectuales es en la subsistencia formal (trascendente) $)^{13}$ y en los caracteres derivados de ella. ${ }^{14} \mathrm{El} \mathrm{Doc}$ tor Angélico alude a este aspecto en muchos pasajes: «...quaelibet substantia spiritualis est per se subsistens» $(970$, II), «...substantiae intellectuales sunt ipsae formae subsistentes» $(542, \mathrm{I})$, «substantiae enim intellectuales secundum suum genus transcendunt omnem naturam corpoream» (721, I). Haya Segovia, por su parte, se expresa en estos términos: «Así se observa en la demostración ofrecida por Tomás de Aquino para concluir que el alma humana es espiritual y, por ello, subsistente una vez corrompido el cuerpo que informaba». ${ }^{15}$ Ahora bien, si espiritualidad es igual a sub-

10 La expresión 'anima spiritualis', no obstante, sólo aparece explícitamente en un texto extraído por Tomás de Aquino del libro De ecclesiasticis dogmatibus: «Neque duas animas esse credimus in uno homine, sicut Iacobus et alii Syrorum scribunt, unam animalem, qua animatur corpus, et immixta sit sanguini, et alteram spiritualem, quae rationem ministret» (562-563, I. La cursiva es mía)).

11 Con esto, los términos 'sustancia espiritual' y 'sustancia intelectual' tienen el mismo referente. Si quedare alguna duda al respecto, sólo hay que ver la conversión que hace Tomás de Aquino en textos similares (v.g. 42 I/545, I).

12 El autor habla de una elevación de las sustancias intelectuales, pero se refiere a la ayuda sobrenatural para contemplar la sustancia divina (cfr. 243, II).

13 Para S. Orrego las sustancias espirituales son, en el pensamiento tomista, «formas por sí subsistentes» (Orrego, S., El ser como perfección en Tomás de Aquino, Pamplona, Cuadernos de Anuario Filosófico, 1998, pag. 73).

14 Redundante resulta, con esto, la definición que hace J.A. Weisheipl del alma intelectual: «...el alma humana es inmaterial, espiritual y subsistente por derecho propios (Weisheipl, J.A. (trad. Hevia, F); Tomás de Aquino. Vida, obras y doctrina, Pamplona, EUNSA, 1994, pag. 274).

15 Haya, F., Tomás de Aquino ante la crítica, Pamplona, EUNSA, 1992, pag. 210. La cursiva es mía. 
sistencia formal, formalidad subsistente será igual a espiritualidad. J. Rassam, en este sentido, deduce la espiritualidad del alma humana de su estatuto de forma subsistente: ${ }^{16}$ «es espiritual toda forma que tiene directamente, sin el intermediario de una materia, potencia para ser». ${ }^{17}$ Por lo demás, Santo Tomás dice que «...omnis substantia intellectualis est incorruptibilis» $(541, \mathrm{I})$ y que «....generari et corrumpi et alia huiusmodi, haec sunt propria substantiarum materialium...» (541, I), pero la ingenerabilidad y la incorruptibilidad son caracteres derivados ${ }^{18}$ («ubi autem non est compositio formae et materiae, ibi non potest esse separatio earundem. Igitur nec corruptio» $(541-542, \mathrm{I})$ ). Por lo demás, decir que las sustancias espirituales son formas subsistentes es como decir que son «substantiae completae simplices» $(543$, I) (en lo que a la composición materia-forma se refiere). En este marco doctrinal se inscriben expresiones tales como «corpora spiritualia» $(979$, II) y «spiritualis magnitudo» (205, I); los cuerpos espirituales son los que están totalmente sujetos al espíritu (resurrección) (cfr. 979, II) ${ }^{19}$ y las magnitudes espirituales son la potencia y la bondad (en definitiva, la perfección) (cfr. 205, I). También tiene su razón de ser en este contexto la contraposición que establece nuestro autor entre spiritualia y corporalia (v.g. 421, I).

«En los ángeles y en las almas humanas su ser se distingue realmente de la esencia, de manera que estas substancias están compuestas de esencia y ser. Sin embargo, su esencia es únicamente forma, no contiene ninguna materia». ${ }^{20}$ «El alma humana es (...) una forma que posee el acto de ser por sí misma, puesto que su acto propio, la intelección, no depende directamente de un órgano corporal. Es una forma subsistente... ${ }^{21}$ J.A. Weisheipl hace unas consideraciones que, aunque basadas en unos textos del De potentia, remiten a las argumentaciones vistas:

...el alma racional difiere de todas las otras formas de la naturaleza, en que las otras no subsisten en su propio esse, sino que más bien son el medio por el que el compuesto existe. El alma racional, sin embargo, es única en cuanto que es capaz de subsistir por una existencia apropiada a su naturaleza, la cual puede ser determinada por sus operaciones.22

También merece la pena reproducir un texto de Blas López Molina:

La noción de 'anima' (alma) en Santo Tomás es síntesis de la noción griega 'psiché' (principio vital inmanente) y la noción cristiana 'pneuma' (espíritu trascendente) (...). Santo Tomás introdujo patrones aristotélicos en las concepciones bíblico-cristianas. Sintetizó la 'psiché', principio vital inmanente de los griegos, centrada, según Aristóteles, en el caso del hombre en su mente, 'pues esto es, sobre todo, lo que constituye al hombre', y el 'pneuma', espíritu trascen-

16 Cfr. Rassam, J. (trad. Urbistondo, J.), Introducción a la filosofía de Santo Tomás de Aquino, Madrid, Rialp, 1980 , pag. 57. Unas palabras de este autor pueden inducir a equívocos: «el alma humana es espiritual porque es subsistente» ibidem, pag. 142). Aún dejando pasar el lapsus de identificar la mera subsistencia con la espiritualidad en Tomás de Aquino, la máxima no es muy feliz, pues subsistencia formal y espiritualidad no son dos cosas diversas que se impliquen mutuamente para nuestro autor.

17 Ibidem, pag. 56.

18 «Siendo sustancia, el alma racional no está afectada por la comupción del cuerpo (...). Toda sustancia, que es una forma, es indestructible por definición» (Gilson, E. (trad. Múgica, F.), El tomismo. Pamplona, EUNSA, 1989, pag. 345).

19 «...he writes about the resurrected body as being spiritualised and perfectly attuned to its (beatified) soul's orientation to God...» (Quinn, P., Aquinas, Platonism and the knowledge of God, Aldershot, Avebury, 1996, pag. 40).

20 Forment, E., Filosofía del ser, Barcelona, PPU, 1988, pag. 123.

21 Rassam, J., op. cit., pag. 56.

22 Weisheipl, J.A., op. cit., pag. 246. 
dente - hombre entero que vive en la dimensión de Dios, y así construyó su concepto 'anima' con un contenido semántico mixto y, por tanto, nuevo. 'Anima es ya principio vital contradistinto del cuerpo, como en lo griego, pero espíritu trascendente -alú lo cristiano-. ${ }^{23}$

López Molina define la espiritualidad como trascendencia, y ésta es una definición exacta: formalidad subsistente y trascendencia son la misma cosa para Tomás de Aquino. Esto ya lo adelantamos al poner 'trascendente' entre paréntesis a la hora de definir la espiritualidad. Por otro lado, fiel reflejo del sentir tomista es la división de la realidad en dimensiones que se hace en el texto reproducido y que Haya Segovia también recoge::24 Dios, el alma intelectual y las sustancias separadas habitan en exclusividad una dimensión, la dimensión espiritual, el mundo del espíritu, mientras que las almas inferiores y los cuerpos se inscriben en la dimensión corporal, el mundo de los cuerpos.

En ello estará, también, en esta naturaleza espiritual del entendimiento humano, su semejanza con Dios. Por él, el hombre es, en ese ser 'más o menos perfectos en razón de la medida de su participación', cercano a los ángeles. Por él, el hombre participa de otro universo, el del espíritu, participación mucho más próxima de la naturaleza de Dios. ${ }^{25}$

El concepto de dimensión (o mundo) es clave pues nos permite entender la convivencia de espíritu y cuerpo en un ente único, el hombre.

Ateniéndose a esta doctrina pienso que no es justo poner en boca de Santo Tomás, como hace Dubarle, una división entre ser divino y ser espiritual ${ }^{26} \mathrm{Y}$ esto aunque se quiera significar con 'divinidad' espiritualidad divina, pues, si el Espíritu divino es el Espíritu Santo, ¿qué sucede con las otras personas de la Trinidad?

Ahora bien, hemos definido lo espiritual como condición del alma humana y hemos aplicado el término 'spiritus' a toda sustancia intelectual, pero el Doctor Angélico habla del espíritu en la Suma contra los gentiles en cuatro sentidos más. Veamos los tres primeros:

- Con 'spiritus corporalis' (cfr. 603, I) o 'spiritus vitalis' (cfr. 727, II) se refiere el autor a una mera dimensión corporal mediante la cual el alma mueve (mediación operativa (cfr. 603, I)) los miembros. Este espíritu material goza de una doble función: motora (cfr. $603, \mathrm{I})^{27}$ y formativa (cfr. 704, I). ${ }^{28}$

- Otro sentido apunta a la etimología de la palabra: 'spiritus' se usa para referirse a los vientos y a todo tipo de fenómenos meteorológicos vinculados con corrientes violentas de aire. El autor sólo utiliza el término en este sentido en citas textuales de otras fuentes (v.g. 399, I, 313, II, 544, II, 695, II).

- En el siguiente comentario al Génesis y en otros textos parecidos se utiliza el vocablo para aludir al alma espiritual (sentido ontológico fundamental) pero con la intención de destacar

23 López Molina, B., El hombre, imagen de Dios, Granada, Universidad de Granada, 1987, pag. 107.

24 Cfr. Haya, F., op. cit., pag. 203.

25 López Molina, B., op. cit., pag. 107.

26 Cfr. Dubarle, D., Santo Tomás teólogo del Cosmos, Granada, Universidad de Granada, 1953, pag. 30.

27 «Anima enim omnes operationes suas efficit per suas potentias; unde mediante potentia movet corpus; et adhuc membra mediante spiritu [corporali]; et ulterius unum organum mediante alio organos $(603, \mathrm{I})$.

28 «Non igitur ipsamet virtus quae cum semine deciditur et dicitur formativa, est anima, neque in processu generationis fit anima: sed, cum ipsa fundetur sicut in proprio subiecto in spiritu [corporali] cuius est semen contentivum, sicut quoddam spumosum, operatur formationem corporis prout agit ex vi animae patris...» (704, I) 
su origen (sentido etimológico) y no su estructura interna o su relación con otras realidades: «sic igitur Deus inspirasse in faciem hominis spiraculum dicitur, quia spiritum vitae homini dedit, non eum ex sua substantia decidendo» (690-691, I). El término 'spiritus' es un derivado directo de 'spiraculum' o 'inspirare', y Tomás de Aquino piensa que el origen etimológico de la palabra se corresponde con el origen real del espíritu humano.

El autor recoge en un texto los sentidos en los que para él es legítimo usar el término 'spiritus'. Las acepciones de esta lista son precisamente las que hemos visto hasta ahora: movimiento de cuerpo aéreo, vapor sutil difundido por los miembros de los animales para sus movimientos y fuerzas y sustancias invisibles y motoras (cfr. 735-736, II). Al margen de esto, en la Suma contra los gentiles también se alude a otras fuentes, como a los saduceos, para los que, según dice Santo Tomás en el capítulo XCI del libro II, un espíritu es una sustancia intelectual completamente separada; o a Salomón, que, según nuestro autor, habla de espíritu por contraposición a cuerpo (cfr. 656, I); o a Hermes, que, según el Aquinate, excluye el sensus del spiritus (cfr. 415, II).

Un último sentido merece atención aparte; y es que Sto. Tomás utiliza el término con esta significación en buena parte de la Summa contra gentiles, y esto hasta el extremo de que en la segunda mitad del libro IV es el único significado que adquiere el vocablo. La primera aproximación a esta acepción la encontramos en un texto del libro III. Allí, hablando del pecado, dice el autor:

Mortale autem est quod animam spirituali vita privat. Cuius quidem vitae ratio ex duobus sumi potest, secundum similitudinem vitae naturalis. Vivit enim corpus naturaliter per hoc quod animae unitur, quae est ei principium vitae. Corpus autem, vivificatum per animam, ex seipso movetur: sed corpus mortuum vel immobile manet, vel ab exteriori tantum movetur. Sic igitur et voluntas hominis, cum per rectam intentionem ultimo fini coniungitur, quod est eius obiectum et quodammodo forma, et vivida est; et, cum per dilectionem Deo et proximo inhaeret, ex interiori principio movetur ad agendum recta. Intentione autem ultimi finis et dilectione remota, anima fit velut mortua: quia non movetur ex seipsa ad agendum recta, sed vel omnino ab eis agendis desistit, vel ad ea agenda solum ab exteriori inducitur, scilicet metu poenarum (527-528, II. La cursiva es mía).

Pues bien, en este fragmento se introduce una distinción entre vita naturalis y vita spiritualis. Esta dualidad no se corresponde exactamente con la formada por el autor con res naturalis y res spiritualis (cfr. 410, II). Y es que, siendo el alma res spiritualis y, por tanto según su propia doctrina, inmortal para Tomás de Aquino y hablando el texto de la posibilidad de que el anima intellectualis pierda la vida espiritual, se ha de considerar que la vita spiritualis no es para Sto. Tomás la única vida de las sustancias inmateriales. Con esto, la sustancia intelectual, en su opinión, goza de una vida natural, inacabable por naturaleza («animae vita perpetua est» $(945$, II)), en tanto que cosa natural y, en determinadas circunstancias, de una vida espiritual sobrenatural en tanto que cosa espiritual; y por eso se dice en el texto que el alma, sin vida espiritual, está velut mortua, y no muerta. Ahora bien, si el alma no goza de vida espiritual por naturaleza, según el Aquinate, y en tanto que, para él, «vivere autem viventium est ipsum esse eorum» (337, I), 'anima intellectualis' y 'spiritus' no pueden apuntar a la misma realidad sustancial en este fragmento de la Summa, a no ser que pensemos que el ser del viviente es la vida natural para el Doctor Angélico (así, podría hablar de un espíritu sin el vivir que le es propio con total coherencia). Este problema queda resuelto con el concepto tomista de generación espiritual, que ahora veremos. 
Sto. Tomás pone en relación esta acepción con los sacramentos: «Sic igitur et huiusmodi res visibiles salutem spiritualem operantur» $(880$, II). Si bien el autor refiere cada sacramento a un aspecto de la vida espiritual, el que más nos interesa a nosotros es el bautismo:

Vita spirituali privatus est homo in sua origine per peccatum originale (...); et adhuc quaecumque peccata sunt addita abducunt a vita. Oportuit igitur baptismum, qui est spiritualis generatio, talem virtutem habere quod et peccatum originale, et omnia actualia peccata commisa tollat $(883-884, \mathrm{II})$.

El espíritu no es en este sentido para Tomás de Aquino una condición intrínseca del alma humana, connatural al hombre, sino algo generado en el bautismo. A raíz de esto se puede plantear un nuevo problema: ¿no puede ser que el autor se refiera a una generación de índole espiritual y no a una generación del espíritu? No. Y es que, aunque, ciertamente, desde el punto de vista gramatical la cuestión quedaría sin respuesta, atendiendo al contexto de la comparación establecida en la Suma entre vida espiritual y vida natural, podemos decir que, al igual que el de generación natural, el concepto de spiritualis generatio tiene un sentido concreto y bien definido en Sto. Tomás.

En este marco doctrinal, y atendiendo a la tesis teológica de Tomás de Aquino acerca de la pérdida de la espiritualidad con el pecado original, se han de contextualizar las ideas tomistas de resurrección espiritual de las almas (cfr. 941, II) y de regeneración espiritual (cfr. 915, II): la vida espiritual es, para nuestro autor, algo que el alma puede ganar y perder en función de su intención al fin. Y con esto podemos solucionar el problema que antes quedó planteado: si la generación de la vida espiritual es entendida como una generación del espíritu, es incoherente (con esta acepción) pensar en un espíritu privado de su vida propia.

Con todo esto, el concepto de spiritus adquiere un sentido completamente nuevo en la recta final de la obra. Es el concepto subyacente a las expresiones 'spiritualis generatio' y 'spiritualis vita' ${ }^{29}$ Y es que, como habíamos dicho, el hombre está compuesto de espíritu y cuerpo para nuestro autor; si ahora éste habla de una generación espiritual y de un alma privada de la vida espiritual, es porque está haciendo uso del término 'spiritus' en otro sentido al de condición natural del alma. Pues bien, en tanto que relacionado con la redención, con el misterio de la encarnación, con el pecado original y con la salvación eterna, podemos denominar 'teológico' a este sentido del concepto de espíritu. Esta acepción teológica del término 'spiritus' se distingue claramente del sentido ontológico-antropológico-filosófico, que es el fundamental en la obra.

\section{LA MENS COMO NÚCLEO FUNDAMENTAL DEL ESPÍRITU}

«El hombre así ya no es 'imagen de' Dios en su totalidad humana; su 'ser imagen' no es coextensivo a su ser total cuerpo-alma, ni siquiera al alma sola, sino al núcleo más irreductible de la 'psyche' humana, aquél que es propio exclusivamente del hombre: la mente o logos». ${ }^{30}$

29 Derivados del concepto de vida espiritual son augmentun spirituale (882, II), mutrimentum spirituale (883, II), spiritualis sanatio (883, II), spiritualis curatio (915, II), salus spiritualis $(917, \mathrm{II})$ y spiritualis medicina (922, II).

30 López Molina, B., op. cit., pag. 107. Es muy discutible la igualación mente-logos. Sin embargo, lo que aquí nos interesa realmente es la consideración de la.mens como el núcleo fundamental del spiritus por su fidelidad a la doctrina tomista. 
Para nuestro autor, mens no es lo mismo que intellectus, como deja entrever en textos como éste:

His autem testimoniis Evangelicis Apollinaris convictus, confessus est in Christo animam sensitivam fuisse: tamen sine mente et intellectu, ita quod Verbum Dei fuerit illi animae loco intellectus et mentis (775, II. La cursiva es mía).

Se trata el entendimiento de uno de los componentes de la mente: «Deinde oportet ostendere quod Deus cogitationes mentium et voluntates cordium cognoscat» (267, I. La cursiva es mía). Pero sólo de uno de ellos. La mente constituye un entramado sustantivo, el entramado sustantivo del alma, compuesto por entendimiento, voluntad, un deseo natural de conocimiento y un principio intrínseco de ciencia. No obstante, el entendimiënto es la parte fundamental. Y es que el primer motor en el hombre es el intellectus (cfr. 571, I). En tanto que el objeto de la voluntad es el bien entendido, hay prioridad del entendimiento sobre la voluntad y sus actos (cfr. 90, II). ${ }^{31} \mathrm{Y}$ esta prioridad es casi absoluta (cfr. 158-159, II).

Veamos los componentes de la mente uno por uno.

\subsection{Entendimiento}

Tomás de Aquino reconoce al entendimiento dos operaciones propias: asentir (cfr. 180, II) y pensar (cfr. 208, I). Hace corresponder, con algún matiz que enseguida veremos, la primera con la fe (cfr. 180, II) y la segunda con la razón (cfr. 106, I). ${ }^{32}$ Y es que el obiectum propio (en el sentido del bien y el fin (cfr. 686, I)) del intellectus es la verdad (cfr. 425, II), el ens in conmuni, ${ }^{33}$ la quididad de la cosa (cfr. 427, II), sin restricciones. En efecto, lo propio del intellectus es el conocimiento (cognitio) ${ }^{34}$ de la verdad, ya sea ésta de fe o de razón: «si igitur contrariae cognitiones nobis a Deo immitterentur, ex hoc a veritatis cognitione noster intellectus impediretur» $(112, \mathrm{I}){ }^{35}$ Ratio $^{36}$ y fides, cogitare y assentire, son las dos vías mediante las cuales el entendimiento alcanza la verdad. ${ }^{37}$ Sólo en este marco doctrinal encuentran sentido pleno frases como «...intellectus, qui est

31 Esta tesis también se podría derivar del siguiente postulado: la fe, que se presenta a la mens, tiene como una de sus funciones despertar en ella el deseo de lo superior (cfr. 106, I). «But because the intellectual power is the most important of the powers of the soul, the intellectual soul itself is sometimes called the intellect» (Kenny, A., op. cit., pag. 42).

32 «Así como el acto propio del intellectus es el entender o inteligir, lo propio de la ratio es la cogitatio...» (Moya, P., El principio del conocimiento en Tomás de Aquino, Pamplona, EUNSA, 1994, pag. 190):

33 Cfr. Murillo, J.I., Operación, hábito y reflexión, Pamplona, EUNSA, 1998, pag. 22.

34 El conocimiento es el resultado de la asimilación de lo conocido por lo cognoscente (cfr. 642, I).

35 En el anima no hay contrarios como tales (277, I).

36 El autor habla en alguna ocasión de ratio demonstrativa (v.g. 121, I). Aunque no lo diga explícitamente, está claro que pretende referirse a un tipo concreto de ratio y no calificar genéricamente a la razón. Más adelante diremos algo más sobre esta razón.

37 El autor, no obstante, descuida en muchos pasajes la operación de assentire y absolutiza la de cogitare. Así, llega a hablar de la cogitatio y la voluntas como las dos potencias del alma: «Ens autem in anima est quod est in voluntate vel cogitatione. Relinquitur igitur quod Deus ea quae sunt in cogitatione et voluntate cognoscat» (267, I). Pero esta reducción no ha de ser tomada literalmente, pues su intencionalidad es la de destacar una operación completamente humana sobre otra que, aunque sea producto de la mente, depende para su ejecución de la llamada de Dios, sobre otra que, aunque perfectísima por parte del objeto, es imperfectísima por parte del entendimiento (cfr. 180, II). Para demostrar que la reducción tomada al pie de la letra es contraria al pensamiento de Tomás de Aquino, baste reproducir un texto: «Per hoc ergo quod 
rationis origo» $(239, \mathrm{I})$ y «... cognitio non est ratiocinativa, sed intellectualis tantum» $(239, \mathrm{I})$; el intelecto no es la razón porque incluye la fe.

J. García López, en una obra sumamente sugerente para nuestra investigación, atribuye a Santo Tomás un concepto estático de la fe y de la razón: «...en la fe se da cogitación y la certeza del asentimiento, con lo cual se distingue de los demás estados de la mente». ${ }^{38}$ Estoy en desacuerdo con esta aseveración. Pienso que fe y razón son ámbitos de operatividad que se corresponden grosso modo con el asentimiento y el pensamiento respectivamente; y el resultado de ambas operaciones es el mismo para Tomás de Aquino. Lo único que varía en el proceso cognoscitivo es el medio por el que se alcanza el conocimiento. Con esto, no se puede hablar, en mi opinión, de un estado mental (de fe) distinto de otro (de razón): la mente, por así decir, tiene siempre el mismo estado, aunque éste se vea modulado en función de la cualidad y la cantidad de los conocimientos adquiridos.

Rudi A. Te Velde publica en 1994 un maravilloso estudio acerca de las relaciones razón-fe en la Suma contra los gentiles en el que atribuye a la razón el estatuto de facultad. ${ }^{39}$ El objeto del estudio es el papel que efectivamente desempeñan ambos ámbitos de operatividad en el desarrollo de la obra y no el pensamiento acerca de los mismos expresado en ella. Ahora bien, en mi opinión, dicha adjudicación no es correcta ni siquiera en este sentido, pues pienso que, en el fondo, no es otro sentido. Te Velde manifiesta su intención de acudir a los textos en los que Sto. Tomás se plantea explícitamente el problema de las relaciones razón-fe; lo hace en muchas ocasiones, aunque ello sólo sea para conseguir una mejor comprensión de su funcionamiento en la obra. Sólo en este contexto, creo, se puede entender la adjudicación del status de facultas a la razón; y es que dicha concesión no puede desprenderse de la mera observación de la puesta en práctica.

La tesis de la «incardinación» de la fe en la mente es completamente original de Sto. Tomás. Sin embargo, aunque algunos autores como García López ${ }^{40}$ contemplan indirectamente la tesis en sus estudios acerca del pensamiento del Doctor Angélico, para la mayoría pasa completamente desapercibida. Tenemos un ejemplo claro de esto en Patrick Quinn, que identifica sin más intellectus y mens en Tomás de Aquino: «Faith therefore extends the range of what can be known about God's nature by providing knowledge that is naturally inaccesible to the human mind...». ${ }^{41}$

Pero el Doctor Angélico introduce en esta clasificación, como hemos dicho, un matiz. Y es que los primeros principios, perteneciendo su conocimiento al ámbito de la razón, son verdades a las que nuestra mente sólo puede acceder por la vía del asentimiento: «Sed in speculativis intellectus de necessitate assentit primis principiis indemonstrabilibus, quorum contrariis nullo modo potest assentire» (298, I). Patricia Moya se percata de esto: «Esto quiere decir que el asentimiento a los principios no es un acto estrictamente imperado, sino natural». ${ }^{42}$ En este sentido, para ser exactos, podemos decir que Tomás de Aquino asocia el pensamiento a la ratio demonstrativa y el asentimiento a la fe y a aquellas verdades de razón evidentes e indemostrables. Podemos decir, por lo

homini de Deo aliqua proponuntur quae rationem excedunt, firmatur in homine opinio quod Deus sit aliquid supra id quod cogitare potest» $(106, \mathrm{I})$.

38 García López, J., Fe y razón, Pamplona, Cuadernos de Anuario Filosófico, 1999, pag. 37. La cursiva es mía.

39 Cfr. Te Velde, R.A., «Natural reason in the Summa contra Gentiles», en Medieval Philosophy \& Theology (4), Indiana, University of Notre Damme Press, 1994, pag. 70.

40 Cfr. García López, J., op. cit., pag. 37.

41 Quinn, P., op. cit, pag. 10.

42 Moya, P., op. cit., pag. 97. La cursiva es mía. 
demás y por todo lo dicho, que el entender, el intelligere, no es una operación más de intelecto, sino la misma operatividad o el resultado del proceso descrito.

Es cierto que el autor habla en el libro II de intelligere y rationari como dos operaciones distintas e independientes la una de la otra: «sed homo habet propriam operationem supra alia animalia, scilicet intelligere et rationari (...)». Pero unas líneas más adelante reduce las dos operaciones al entendimiento: «ergo oportet in homine ponere aliquod principium quod proprie dat speciem homini, quod se habeat ad intelligere sicut actus primus ad secundum» (570, I). Esto sólo es compatible si pensamos que con 'inteligir y razonar', expresión que se vuelve a repetir en varias ocasiones (v.g. 665, I y 547, II), lo que quiere decir el Aquinate es inteligir, en sentido lato, y razonar, en sentido estricto.

\subsection{Voluntad}

El autor aplica a la voluntad el término 'affectio', siendo las afecciones para él ciertas inclinaciones del alma a algo (cfr. 267-268, I). Así, habla en el libro I de las 'affectiones intellectualis' (vs. afecciones sensitivas) (cfr. 313, I). Con esto, con «affectum mentis» (453, II) no se puede referir más que a la voluntas. «Nam experimento apparet quod per corporales actus anima excitatur ad aliquam cogitationem vel affectionem. Unde manifestum est convenienter etiam corporalibus quibusdam nos uti ad mentis nostrae elevationem in Deum» (454, II). Por lo demás, Tomás de Aquino afirma que la mente se apasiona a veces con amor y deseo (cfr. 489, II). Anthony Kenny se expresa en estos términos: «following Augustine, Aquinas thinks of the mind as consisting not just of intellect, but of intellect plus will» ${ }^{43} \mathrm{La}$ voluntad es uno de los «great powers of the mind» para Sto. Tomás.

Tomás de Aquino atribuye a la voluntad fundamentalmente tres actos propios: desear, que se da cuando se tiende a lo que no se tiene todavía, amar, que no sólo surge cuando se tiene el bien (perfecto) sino que también es la causa de que se busque con deseo lo que no se tiene (imperfecto), y deleitarse, que aparece cuando sentimos el bien presente, recordamos el pasado o esperamos el futuro (cfr. 154-155, II). ${ }^{44}$ La delectación es el descanso de la voluntad en algún bien conveniente, mientras que el deseo es la inclinación de la voluntad hacia un bien a conseguir (cfr. 155, Ir); el amor es el punto de intersección entre ambos actos. No obstante, en tanto que principio de todas las afecciones (cfr. 320, I), el amor es también el principio de todos los actos de la voluntad y la raíz común de todos ellos (cfr. 722, II). Hay, por tanto, dos sentidos del término 'amor': acto de la voluntad y raíz de todos los actos de la voluntad.

El autor habla del amor, el deseo y la delectación como los actos fundamentales de la voluntad y, al mismo tiempo, emplea expresiones como «voluntates et electiones» 0 «electiones humanae et voluntatis motus» (v.g. 358, II). Las siguientes palabras nos van a dar la clave para la compatibilización:

Omnis electio et actualis voluntas in nobis immediate ex apprehensione intellegibili causatur: bonum enim intellectum est obiectum voluntatis... (338, II. La cursiva es mía).

43 Kenny, A., op. cit., pag. 42.

44 En algún pasaje nuestro autor incluye el odiar, el entristecerse y el encolerizarse en la lista de los actos de la voluntas (cfr. 722 , II), pero es claro que sitúa dichas acciones en otro nivel. 
En tanto que no es un movimiento de la voluntad y en tanto que es causada inmediatamente por la aprehensión intelectual por ser el bien entendido el objeto de la voluntad, la elección se ha de tratar de un acto del todo espiritual, un acto conjunto de la inteligencia y la voluntad, un acto en el que ambas potencias juegan un papel activo. El siguiente texto avala esta interpretación:

Haec autem responsio sufficiens non est, si ponantur corpora caelestia per se causa electionum nostrarum, utpote per se imprimentia in intellectum et voluntatem $(342$, II. La cursiva es mía).

Etienne Gilson, en su obra El tomismo, se expresa con gran claridad:

¿Qué es, pues, la elección? Es un acto del cual una parte depende de la razón o del intelecto, mientras que la otra parte depende de la voluntad. ${ }^{45}$

Robles Carcedo, por su parte, dice que «en los seres humanos es el 'alma racional' la que nos permite desarrollar las actividades de pensar y de elegir con libertad». ${ }^{46}$ Es cierto que el autor no dice expresamente que sean éstas las únicas actividades del alma espiritual, pero ésta parece ser su idea. El amor, el deseo, la delectación y el asentimiento a las verdades de fe, que, junto con el pensamiento y la elección, constituyen para Tomás de Aquino las operaciones propias del espíritu, son, con esto, obviadas por Robles en este pasaje. J.A. Weisheipl tampoco afina cuando dice: «...el caso del alma racional, cuyas funciones son el pensar y el querer». ${ }^{47}$ Ya dijimos antes que para el Doctor Angélico 'intelligere' apunta a la operatividad del entendimiento, una operatividad que se expresa en dos operaciones distintas, asentir y pensar. Con esto, a la enumeración de Weisheipl le falta una operación. Pero sólo una. Y es que Tomás de Aquino pone en paralelo el intelligere y el velle en múltiples textos (v.g. 662, I) y, así, en tanto que intelligere es la operatividad del intellectus, velle habrá de ser la operatividad de la voluntas, una operatividad que se expresa en las tres operaciones vistas.

\subsection{Un deseo natural de conocimiento ${ }^{48}$}

Si la mente es, al principio, como una tabla rasa, es que, en un primer momento, no posee su fin, no es acto puro; esto conlleva que, en el caso del hombre, exista lo que Aristóteles llamó 'apetito natural de saber' y también, en terminología tomista, 'un hábito natural (intelectual) dado por la naturaleza', ya que el primer acto del intelecto no puede venir determinado más que por la propia naturaleza de la facultad intelectiva. ${ }^{49}$

45 Gilson, E., op. cit., pag. 453. Gilson, no obstante, cuando habla de la estructura del acto humano, desconsidera por completo el deseo, la delectación y la ejecución (Gilson, E., op. cit., pags. 449-455).

46 Robles Carcedo, L., Tomás de Aquino, Salamanca, Universidad de Salamanca, 1992, pag. 200.

47 Weisheipl, J.A., op. cit., pag. 247.

48 Hay tres referencias a este deseo en la Summa contra gentiles: 104, I, 224, II y 225, II.

49 Corazón, R., Fundamento y limites de la voluntad, Pamplona, Universidad de Navarra, 1992, pag. 17. El término 'hábito' no tiene aquí el sentido que es el ordinario en Tomás de quino. Para él el deseo de conocimiento forma parte de la constitución interna de la mens y los hábitos constituyen su disposición; hábito aquí es tendencia natural. 
Este deseo culmina en el conocimiento de la sustancia divina, que es lo que todas las méntes desean naturalmente (cfr. 226, II): «Es claro que [para Sto. Tomás] en el hombre, por su inteligencia, hay un deseo natural de saber, de conocer toda la realidad, deseo que no se sacia sino con el conocimiento de la esencia misma de la causa primera de todo ser ${ }^{50} \mathrm{En}$ tanto que el apetito natural de saber es algo intrínseco a la mens, la mens es algo intrínseco al espíritu y el espíritu es esencial en todos los seres espirituales (alma, ángel y Dios), el deseo natural de conocimiento tiene que estar presente en todos los seres espirituales. Excepto en Dios. Como dice R. Corazón, Dios carece de dicho apetito porque en Él intelecto, voluntad y ser son una sola cosa y porque es un ser perfecto ${ }^{51}$ y es que, si bien es cierto que la potencia intelectual no desaparece aunque no haya nada que pensar y que «cuando uno y otro [fin y bien] se alcanzan, se produce la misma quietud del deseo» ${ }^{52}$ pero la voluntad permanece, también es cierto que el deseo no es una potencia, sino una mera actividad que, como tal, no existe mientras no se realiza. Con esto, se puede hablar de una doble tendencia. La primera de ellas es la tendencia a la semejanza (el hombre se asemeja paulatinamente a Dios conociéndole y amándole); y es que todos los agentes naturales se mueven con un sentido teleológico (y el hombre no sólo no es menos sino que puede conocer el fin perseguido) ${ }^{53} \mathrm{La}$ segunda es la tendencia al conocimiento en general ${ }^{54}$ (que culmina con el conocimiento de la sustancia divina). De nosotros depende compatibilizar, unificar, o no ambas tendencias:

Est enim quoddam desiderium hominis inquantum intellectualis est, de cognitione veritatis: quod quidem desiderium homines prosequuntur per studium contemplativae vitae. Et hoc quidem manifeste in illa visione consummabitur, quando, per visionem Primae Veritatis, omnia qua intellectus naturaliter scire desiderat, ei innotescent (258, II).

La última de estas tendencias se inscribe en la mens, pero la primera, en tanto que afecta a todo el ser y a todos los entes, se ha de adscribir al ser sustancial (en el caso del hombre al ser sustancial en sentido lato y al alma en sentido estricto).

Pero veamos el texto en el que se atribuye explícitamente el deseo de conocimiento a la mente:

Quem quidem laborem pauci subire volunt pro amore scientiae, cuius tamen mentibus hominum naturalem Deus inseruit appetitum (104, I).

Patricia Moya, en su libro El principio del conocimiento en Tomás de Aquino, se refiere en unos términos muy acertados a este deseo natural de conocimiento:

Hay una inclinación preconsciente y prevoluntaria del entendimiento a la realidad. Se puede decir que esta es la manera según la cual el entendimiento está en la realidad 'por naturaleza'. El logos del entendimiento es, ante todo, esa inclinación natural. Pero se trata de una inclinación natural in genere y no específicamente dirigida al conocimiento de los principios,

50 Orrego, S., op. cit., pag. 74-75.

51 Cfr. Corazón, R., op. cit., pag. 20.

52 Álvarez Gómez, Ángel, La Suma contra los gentiles de Tomăs de Aquino, Madrid, Alianza, 1998, pag. 38.

53 Cfr. Roca Blanco, D., Santo Tomás de Aquino, Madrid, Ediciones del Orto, 1994, pàg. 45-46.

54 «Est autem appetitus naturalis intellectus ut cognoscat omnium rerum genera et species et virtutes, et totum ordinem universi: quod demonstrat humanum studium circa singula praedictorum» (247, II). 
aunque el conocimiento de éstos esté estrechamente vinculado a esta inclinación natural por su relación con el conocimiento del ente. ${ }^{55}$

Patrick Quinn también alude a este deseo, aunque lo refiere exclusivamente al conocimiento de la esencia de las cosas. ${ }^{56}$ Por su parte, García López habla de este «apetito natural de saber», pero atiende especialmente a su fin, el conocimiento de Dios, y a la ayuda sobrenatural necesaria para su culminación. ${ }^{57}$ En este marco, y en tanto que el autor de la Suma Teológica habla de este deseo como una tendencia a rehuir la ignorancia y no cierta ignorancia (cfr. 225, II), el «desiderium cognoscendi causas» $(149$, II) sólo puede ser entendido como una de las dimensiones de este apetito. Ahora bien, basándonos en la tesis tomista de que el entendimiento es absolutamente prioritario a la voluntad podemos decir que, para Tomás de Aquino, no depende de nuestra voluntad la actualización de la potencia intelectual; y para no recurrir a un principio extrínseco que anule nuestra libertad de acción, hay que pensar que el deseo natural de conocimiento no es una tendencia exterior al entendimiento para nuestro autor sino una condición natural de la misma inteligencia y de su ejercicio.

\subsection{Un principio intrínseco de ciencia}

Et quia exterior operatio docentis nihil operaretur nisi adesset principium intrinsecum scientiae, quod inest nobis divinitus $(632-633, \mathrm{I})$.

Se pueden reconocer hasta tres acepciones de la palabra 'scientia' en la Suma contra los gentiles: conocimientos («ex multis intellectis intelligentis scientia integratur» $(220, \mathrm{I})$ ), conocimiento (hábito de la ciencia + especies inteligibles + conocimientos) (cfr. 631, I) y hábito (habitualis scientia (cfr. 237, I), virtud contemplativa (cfr. 331-332, I)). El significado del término tal y como aparece en el texto reproducido es fácilmente vislumbrable por el contexto («omnis disciplina ex praeexistenti fit cognitione» $(632$, I)): 'ciencia' apunta aquí a 'conocimientos'. Pero, ¿a qué conocimientos se está refiriendo Tomás de Aquino? Basándonos en lo que se dice en el libro I podemos decir que se trata del conocimiento de los primeros principios: «principiorum autem naturaliter notorum cognitio nobis divinitus est indita: cum ipse Deus sit nostrae auctor naturae» $(111, \mathrm{I})$. En el libro II este extremo es confirmado definitivamente. Y es que allí, un poco antes de exponerse la tesis de que la mens incluye un principio intrínseco de ciencia, nos dice el Angélico lo siguiente: «in eo enim qui docetur, est principium activum ad scientiam: scilicet intellectus, et ea quae naturaliter intelliguntur, scilicet prima principia» $(632, \mathrm{I})$. Esto sólo puede significar que el principio intrínseco de ciencia no es una serie de inteligidos sino eso, un principio, un principio de conocimiento inmediato para determinados objetos, el conocimiento (como principio) de los principios; además, el autor habla de principio intrínseco de ciencia, y no de determinada ciencia.

Cabe reconocer dos entradas de la expresión 'conocimiento natural' en la Summa. Tras decir que «naturaliter igitur intellectus noster cognoscit ens» $(681, \mathrm{I})$, Tomás de Aquino afirma que «haec 
igitur sola principia intellectus noster naturaliter cognoscit, conclusiones autem per ipsa» (681-682, I). En tanto que «in qua cognitione [esse] fundatur primorum principiorum notitia» $(681, \mathrm{I})$, ens no es lo mismo que principia. Con esto, 'conocimiento natural' tiene en cada una de las frases un sentido distinto: en la primera, conocimiento natural se opone a conocimiento sobrenatural o revelación, siendo el conocimiento natural el que depende exclusivamente de las fuerzas naturales del hombre; en la segunda, conocimiento natural se opone a conocimiento mediado («universalibus principiis, quae nullus ignorat, sed sunt ab omnibus eodem modo et naturaliter cognita» (680-681, I) $\left.{ }^{58}\right)$. Y, así, en este segundo sentido ha de entenderse el conocimiento de los primeros principios: «cognitio principiorum est nobis naturalis» $(681, \mathrm{I})$. Con esto, «principiorum autem naturaliter notorum cognitio nobis divinitus est indita: cum ipse Deus sit nostrae auctor naturae» (111, I); en efecto, si se trata de un conocimiento no buscado sino natural, del autor de nuestra naturaleza será su autoría. Ahora bien, que el conocimiento de los primeros principios sea inmediato e introducido por Dios no quiere decir que salga a la luz sin necesidad de experiencia, pues los primeros principios se conocen a partir de la inducción, que requiere el conocimiento más o menos amplio de los singulares; ${ }^{59}$ no obstante, la experiencia necesaria para este conocimiento es mínima. ${ }^{60}$ «Sed ipsorum principiorum cognitio in nobis ex sensibilibus causatur: nisi enim aliquod totum sensu percepissemus, non possemus intelligere quod totum esset maius parte» (682, I). Y tampoco quiere decir que no requiera de la luz del entendimiento agente. «Cognitio quae fit per aliquid naturaliter nobis inditum, est naturalis: sicut principia indemonstrabilia, quae cognoscuntur per lumen intellectus agentis» (206, II). Ahora, si el conocimiento de los primeros principios es un conocimiento habitual y el hábito del intellectus no es un hábito infuso (cfr. 558-562, II) sólo cabe pensar en el entendimiento agente como el principio intrínseco de ciencia. Es cierto, los primeros principios se manifiestan al hombre gracias a la luz del intelecto agente, que le es natural; ${ }^{61}$ y éste es precisamente el principio intrínseco de ciencia. «Lo que es dado por Dios no es el conocimiento mismo de los principios, sino la facultad que es el principio inmediato de operación por la cual somos capaces de poseer los primeros principios». ${ }^{62}$

\section{EL ANIMUS COMO DISPOSICIÓN HABITUAL DEL ANIMA SPIRITUALIS}

«Ita etiam de his quae sunt in anima nostra, scilicet potentiis et habitibus,...» (209, II). El alma, de este modo, se divide en dos partes fundamentales para Tomás de Aquino: potencias y hábitos. Pues bien:

Homo dicitur bonus vel malus secundum virtutem vel vitium, quae sunt habitus quidam. Habitus autem a potentia in hoc differt quod per potentiam sumus potentes aliquid facere: per habitum autem non reddimur potentes vel impotentes ad aliquid faciendum, sed habiles

58 De este modo no todos los sujetos tienen la misma opinión con respecto a las conclusiones pero sí con respecto a los principios (cfr. 681, I).

59 Cfr. Moya, P., op. cit., pags. 59-61.

60 Cfr. ibidem, pag. 152.

61 Cfr. ibidem, pag. 71.

62 Ibidem, pag. 87. 
vel inhabiles ad id quod possumus bene vel male agendum. Per habitum igitur neque datur neque tollitur nobis aliquid posse: sed hoc per habitum acquirimus, ut bene vel male aliquid agamus (935, II. La cursiva es mía).

Así, la potencia capacita, el hábito habilita para; la potencia faculta, el hábito dispone hacia. «El hábito está en el orden de los medios para la acción, es decir, es una cualidad o disposición que capacita para la acción; que habilita a la potencia». ${ }^{63}$

Ahora bien, el animus no es definido explícitamente por el Aquinate en la Suma contra los gentiles. Es más, el término en cuestión sólo aparece 25 veces en toda la obra. No obstante, la división del alma en potencias capacitadoras y hábitos disponentes y el siguiente texto confirman la tesis de que el animus es la disposición habitual u operativa del alma.:

Non est possibile quin in homine concupiscentiae venereorum aliquae oriantur: cum naturales sint. Resistere autem omnino concupiscentiis, et quasi continuam pugnam habere, maiorem inquietudinem animo tribuit quam si aliquis moderate concupiscentiis uteretur. Cum igitur inquietudo animi maxime perfectioni virtutis repugnet, videtur perfectioni virtutis adversari quod aliquis perpetuam continentiam servet $(516, \mathrm{II})$.

Resistir a las concupiscencias, regular las pasiones, es competencia de la razón (cfr. 313-314, I) y la razón es una de las dimensiones de la potencia espiritual llamada inteligencia. Pues bien, en tanto que «resistere (...) omnino concupiscentiis (...) maiorem inquietudinem animo tribuit» y el resistir pasiones no puede dar, otorgar, tribuere, nada al mismo resistir, el animus se ha de corresponder con la parte no potencial del alma, a saber, los hábitos.

Este texto, que, si bien literalmente confirma la tesis, considerado de modo aislado nos deja un sabor agridulce, cuenta con el apoyo de una serie de referencias en la que se puede vislumbrar el principio más intuitivamente y con mayor profundidad. Me refiero al catálogo de atribuciones al animus. Y es que la mayoría de estas atribuciones sólo puede entenderse en términos dispositivohabituales. ${ }^{64} \mathrm{El}$ primer ejemplo lo encontramos en el fragmento que acabamos de reproducir: «inquietudo animi». Y es que la inquietud no es un acto de la voluntad, ni mucho menos de la inteligencia, sino una disposición hacia, una disposición que afecta al alma por cuanto determina nuestro comportamiento voluntario pero que en sí misma no es ningún comportamiento. La expresión «prompto animo» $(511$, II) es también bastante clarificadora; y es que con ella se refiere Tomás de Aquino a lo que nosotros en el lenguaje cotidiano denominamos precisamente 'disposición (para)'. En efecto, afrontar las cosas prompto animo es para nuestro autor enfrentarse a ellas con determinación; y esta misma determinación no es un acto de voluntad ni de inteligencia, sino algo que dispone para la acción. La aplicación al animus de términos como 'extollentia', 'elatio' (cfr. 513, II) o 'praesumptio' (cfr. 107, I) es muy ilustrativa y contribuye a hacer aún más plausible nuestra inter-

\section{Ibidem, pag. 129.}

64 «...Tomás de Aquino define claramente los límites de la noción de hábito respecto a la de disposición, dejando claro que el hábito es la disposición difícilmente móvil y que, por lo tanto, se da propiamente sólo en las potencias que no radican en un sujeto material. A veces, no obstante, se habla de la salud o de otras disposiciones como hábitos o disposiciones habituales, pero esto se debe solamente a un uso más general e impropio del término hábito» (Murillo, J.I., op. cit., pag. 51). En efecto, existen, como antes dijimos, disposiciones no habituales, las disposiciones de; por lo demás, disposiciones como la salud son disposiciones corporales que, como tales, no nos interesan aquí. 
pretación: la arrogancia no es un acto, sino una praeparatio ad. La expresión «animi libertas» (497, II), aunque pudiera parecer conflictiva, apoya la interpretación que defendemos. ¿Cómo, después de haberse atribuido la libertad a la voluntas, se puede hablar de libertad de ánimo? La única solución está en pensar en una libertad actual y en una libertad dispositiva: la libertas arbitrio es la libertad propiamente dicha, la libertad en su ejercicio, mientras que la libertas animi es una disposición del alma hacia la auténtica libertad. Veamos, por último, un texto en el que se puede ver claramente lo que venimos diciendo:

Patet enim quod electiones nostrae multiplicitatem habent: cum in diversis et a diversis diversa eligantur. Mutabiles etiam sunt, tum propter animi levitatem, qui non est firmatus in ultimo fine, tum etiam propter mutationem rerum quae nos extra circumstant (360, II).

Hay algunos textos que, aunque en principio parezcan problemáticos, si se analizan detenidamente, pueden compatibilizarse con lo expuesto. Los vamos a ver uno a uno y, al hilo, diremos algunas cosas más del animus:

— «...hoc fit vel ad removendum hominis animum a crudelitate in homines exercenda...» (441, II). Si los hábitos no son actos, ¿qué sentido tiene afirmar que compete al animus practicar? Y es que el autor quiere dejar constancia de que, aunque el que actúa, el que practica, es el hombre como un todo, de lo que se trata es de trocar el hábito que a la práctica de la crueldad conduce.

— «Ut ergo ab hac praesumptione humanus animus liberatus ad modestam inquisitionem veritatis perveniat, necessarium fuit homini proponi quaedam divinitus quae omnino intellectum eius excederent» $(107, \mathrm{I})$. ¿Es propio del ánimo buscar la verdad? No; lo que pertenece al animus es la modestia o inmodestia determinantes de un tipo u otro de búsqueda. Y es que Santo Tomás atribuye en muchos lugares impropiamente al animus lo que, perteneciendo al anima o al hombre como un todo, depende en gran medida de la disposición habitual.

- «...quibus animos mortalium assentire et maximum miràculorum est, et manifestum divinae inspirationis opus, ut, contemptis visibilibus, sola invisibilia cupiantur» $(109, \mathrm{I})$. Pero, ¿no dijimos antes que el assentire es una operación del intelecto? ¿Cómo, entonces, se puede afirmar ahora que el asentimiento a las verdades divinas compete al animus? Lo que el Aquinate parece insinuar es que se puede estar bien o mal dispuesto para asentir y no que el ánimo sea realmente el sujeto del asentimiento. Por lo demás, el hecho de hablar de asentir y desear cuando el tema es el ánimo nos indica que el animus es exclusivo de los seres espirituales para Tomás de Aquino.

- «Si igitur creaturarum bonitas, pulchritudo et suavitas sic animos hominum allicit [seduce], ipsius Dei fontana bonitas, rivulis bonitatum in singulis creaturis repertis diligenter comparata, animas hominum inflammatas totaliter ad se trahet» $(398$, I). En este fragmento no se alude a ningún hábito, pero sí al ánimo. Y es que se habla del animus como fin y no como principio: la bondad y la belleza de las criaturas pueden determinar indirectamente la configuración del ánimo. No obstante, la apreciación de la armonía de un cuadro puede no implicar la creación de un hábito; pero, entonces, el hecho de la apreciación no habrá afectado a la configuración del alma sino, todo lo más, a la composición sustantiva, a la cantidad, al grado de conocimiento o a la intensidad de la voluntad. 
— «Propter quod etiam suis discipulis plenitudinem Spiritus Sancti non dedit quandiu cum eis conversatus fuit quasi per eius absentiam eorum animis ad spiritualia munera magis praeparatis» $(870$, II). Caben dos posibilidades: postular una doble disposición para (del animus y del anima) o pensar que el autor se quiere referir al alma pero habla de ánimo en tanto que sujeto de la praeparatio.

— «Ut igitur hominum animos ab amore mundanae gloriae in amorem divinae gloriae transmutaret» $(874, \mathrm{II})$. El autor habla de un amor, de una caridad, habitual que, en tanto que tal, se atribuye al animus y configura al alma.

Las nociones de praeparatio (Alejandro Afrodisio) y complexio (Galeno) (cfr. 581-587, I) se acercan bastante al concepto de animus, aunque difieren de éste en que, en su pretensión de ser definiciones del alma, apuntan a disposiciones del cuerpo.

Tomás de Aquino habla de dos tipos de hábitos, a saber, virtudes y vicios: «homo dicitur bonus vel malus secundum virtutem vel vitium, quae sunt habitus quidam» $(935$, II). «...in his solis actibus potest esse virtus vel vitium qui subduntur aliqualiter rationi» (842-843, II). A esto añade nuestro autor que «virtutes et vitia sunt electionum principia propria: nam virtuosus et vitiosus differunt ex hoc quod contraria eligunt» (339, II). Ahora bien, que las virtudes y los vicios sean principios de elección no quiere decir que sean los únicos principios de elección: una elección, una acción en general, puede proceder directamente del orden potencial y esto es precisamente lo que para nuestro autor posibilita el trueque de hábitos, la libertad: «Nihil autem prohibet eum qui habitum habet, agere secundum habitum vel contra eum (...). Quod ideo est quia usus habituum in nobis ex voluntate est: voluntas autem ad utrumque oppositorum se habet» (909, II). Además, si la mayoría de los hábitos son adquiridos con la acción, debe haber unas acciones primeras no habituales.

\section{CONCLUSIÓN}

La teoría del alma en particular y la antropología en general de Tomás de Aquino no son una serie de postulados dispersos sin más conexión entre ellos que la comunidad de referencia, sino una doctrina unitaria. Esta es una de las cosas que anticipamos en la introducción y que se desprenden de nuestra investigación acerca de la Suma contra los gentiles. Los estudios sobre la psicología tomista, por regla general, nos presentan a Tomás de Aquino como un autor más o menos coherente en sus planteamientos y sumamente preocupado por el hombre que estableció una distinción entre entendimiento agente y entendimiento posible, que intentó conjugar razón y fe, que habló de diversos tipos de alma, que postuló la existencia de una gran cantidad de disposiciones operativas en el ser humano, que dividió el conjunto de los hábitos en virtudes y vicios... Pero las afirmaciones del Santo dan para una comprensión unitaria de su teoría del alma espiritual. A la dispersión aparente que envuelve los textos de nuestro autor y que se explica por su inquietud y por la premura de su escritura subyace una concepción armónica del hombre. Para el Doctor Angélico el hombre, y su alma, gozan de unidad, de perfecto sentido estructural, en su ordenación al fin: el anima humana es una sustancia de condición espiritual, un entramado sustantivo integrado por la mens, sujeto de la facultad intelectiva (que cuenta con dos ámbitos de operatividad y dos dimensiones operativas) y de la voluntad, y configurado principalmente por una serie de disposiciones habituales, el animus. Cabe establecer una jerarquía entre estos tres elementos. En tanto que condición, condición de un 
alma integrada por un entramado sustantivo y por una serie de disposiciones para que definen el ánimo, el espíritu ocupa el último lugar. Y la mente es lo supremo. En efecto. Es cierto que la forma, en tanto que da el ser al compuesto, supera a la materia; ahora bien, el animo constituye sólo la dimensión operativa del principio formal del anima. Siendo definido por una serie de cualidades dispositivas no esenciales, constituyendo una realidad accidental, adscrita al alma y a la mente pero externa a sus respectivas sustancias, el animus es inferior a la mens.

Pues bien, con la presentación de los tres principios articuladores de la estructura ha sido puesto de manifiesto el carácter unitario de la doctrina tomista, pero sólo el carácter. Anima y spiritus, intellectus y mens, dimensión potencial y animus forman parte de una unidad estructural, pero de una unidad estructural que hasta ahora sólo ha sido apuntada. Nuestra investigación no está cerrada, es un reto, una fuente de sugerencias que exigen una mayor profundización en el tema de la espiritualidad del hombre, una mayor profundización que haga emerger en sí misma dicha unidad.

Gabriel Martí Andrés Becario de investigación

Universidad de Málaga Facultad de Filosofía y Letras Departamento de Filosofía Campus Teatinos Málaga 